\title{
Sedimentary cyclicity from X-ray GT images in Campos Basin, offshore Brazil
}

Marcos Hexsel Grochau and Elisabete Campos, Petrobras

Dariush Nadri, Tobias M. MülleR, and Ben ClenNeLL, CSIRO Earth Science and Resource Engineering

Boris GUREVICH, Curtin University of Technology

$S^{n}$ mall-scale changes in rock properties, such as those resulting from centimeter-scale depositional layering, are usually undetectable in standard borehole logs (Murphy et al., 1984). Even highresolution logs with a small sampling interval (e.g., 2 inches) may still have a relatively large investigation volume. This presents a problem when we wish to capture the full variation in physical properties for purposes such as rock physics modeling.

One method that gives useful information in an automated way and at a higher resolution than downhole logs is $\mathrm{X}$-ray computed tomography (CT) of cores (Mees et. al., 2003). Samples of marine sediment cores are the fundamental source of information on seabed character, depositional history, and environmental change (Rothwell and Rack, 2006). The CT number encodes a combination of mass density and electron density proportional to the mean atomic number.

The environmental conditions during the sedimentation could cause periodic variations of carbonate calcium concentration of the sedimentary environment, reflecting periods of higher and

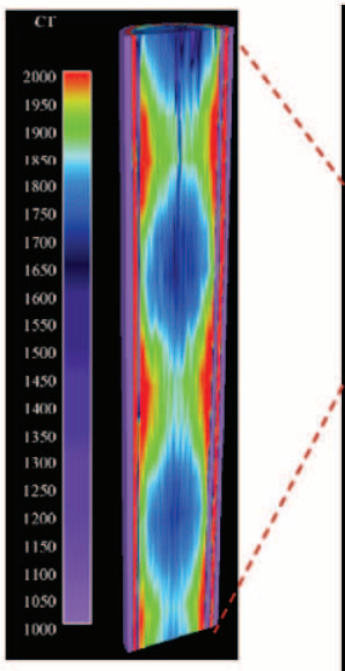

Hounsfield Units (HU)
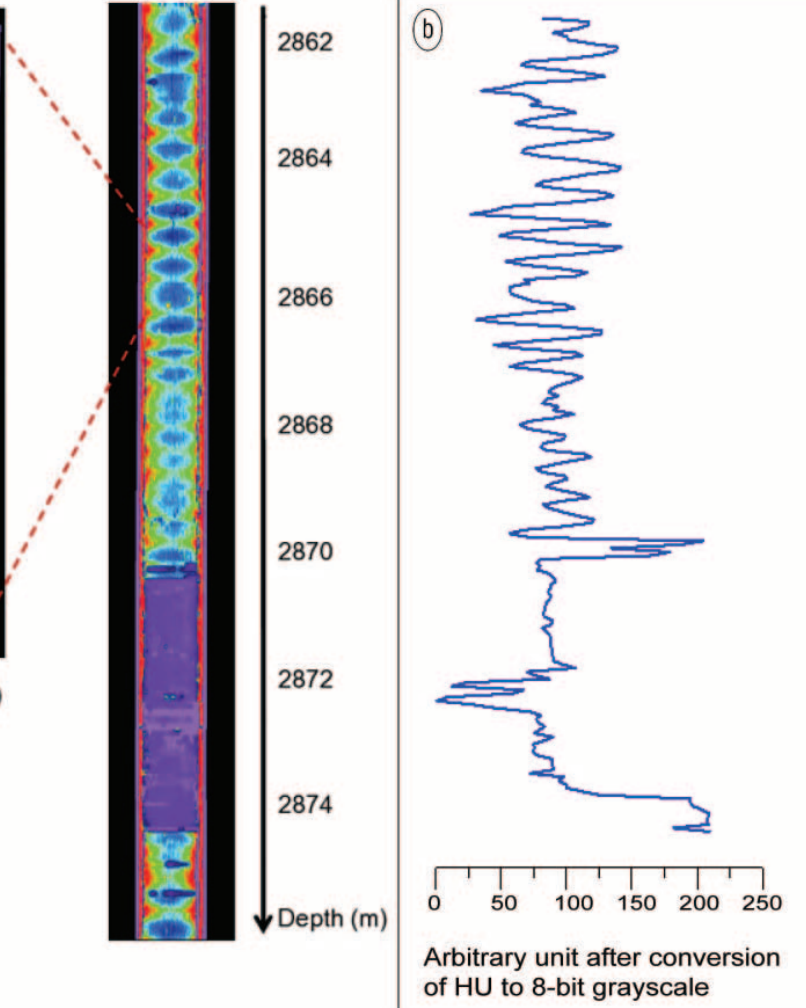

Figure 1. X-ray CT values obtained by computing the average value over a circular area for each of the $143 C T$ images at every $5 \mathrm{~cm}$. Alternating low and high CT values provides evidence of cyclicity. Hounsfield units (a) and arbitrary units after conversion to an 8-bit gray scale (b). lower ratios between pelagic carbonate plankton productivity and terrigeneous (clay, silt) sediment input. Burial diagenesis can enhance the original contrast between the compositionally distinct layers.

In this paper, we take advantage of a unique densely sampled CT and ultrasonic data set in a deep shale environment offshore Brazil to demonstrate that these data provide valuable information on centimeter-scale heterogeneity that can be attributed to sedimentary cyclicity.

\section{The Campos Basin data set}

The data come from a well in Campos Basin, offshore Brazil. The interval is approximately $2800 \mathrm{~m}$ below sea floor, in an Oligocene-to-Miocene hemipelagic sequence of alternating marls and shales that forms the overburden to the main sandstone reservoir. The data set consists of CT images of the whole core, ultrasonic P-wave measurements on core plugs, and well logs.

$\mathrm{X}$-ray CT images were taken every $5 \mathrm{~cm}$ from cores at the depth of around $2800 \mathrm{~m}$. To acquire these CT images, we used a Picker-PQS scanner with X-ray voltage set at $130 \mathrm{kV}$ and current at $100 \mathrm{~mA}$. The time per scan was $4 \mathrm{~s}$ and image resolution was $0.5 \times 0.5 \mathrm{~mm}$. The standard deviation of the $\mathrm{X}$-ray CT value measurements is $0.56 \%$. The slice thickness is $1 \mathrm{~cm}$, meaning that the support volume of the measurements is smaller than the sampling interval. This is an important difference from the high-resolution downhole density log, where the sampling interval is similar $(2$ inches $=5.08 \mathrm{~cm})$, but the support volume is larger $(\approx 10 \mathrm{~cm})$.

Ultrasonic $(500 \mathrm{kHz}) \mathrm{P}$-wave velocities were measured at different pressures on 23 rock samples, providing complementary information about their elastic properties. The measurements were done for horizontally and vertically oriented samples using a varying confining pressure from 1000 to 6000 psi. 


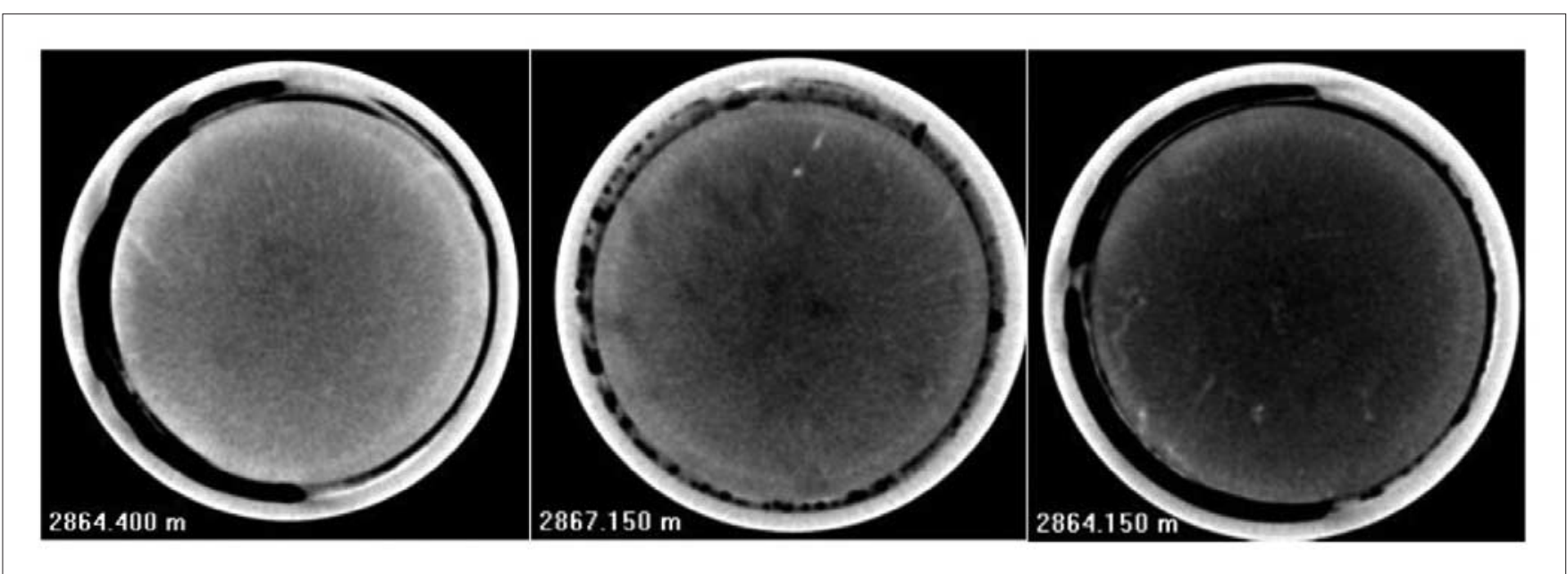

Figure 2. CT images from depths 2864.40 (sample 8V), 2867.15 (sample 16V), and 2864.15 (sample 7V) m. Lower absorption in the right image is due to higher clay content; the image on the left shows higher concentration of carbonate calcium. The image in the middle shows an intermediate concentration of clay and carbonate calcium. The brighter the image, the higher X-ray CT value, density, and velocity.

An extensive suite of borehole logs is also available, which includes high-resolution gamma-ray and density logs with a sample interval of $5.08 \mathrm{~cm}$. The sonic P-and S-velocities were measured by a monopole sonic logging tool with a spacing of $20 \mathrm{~cm}$ (standard) and $5.08 \mathrm{~cm}$ (high-resolution).

\section{Small-scale sedimentary cyclicity and its seismic response}

We initially investigate standard borehole logs over the interval to assess the rock physics properties. The resolution is not enough to detect any lithology intercalation in the rocks immediately above the sandstone reservoir. However, ultrasonic velocity measurements from different depths at different confining pressure show a substantial variation in elastic properties. High-resolution logs show some indications of a cyclic pattern. These logs have a small sampling rate $(5.08$ $\mathrm{cm}$ ); however, the actual resolution is lower because the volume of investigation of various sensors is 2-6 times larger than the frame spacing at which data were collected.

In order to gain better insight about the variation of elastic properties, we use the regularly spaced X-ray CT scans performed on the whole core. We compute the mean X-ray $\mathrm{CT}$ value for each image by averaging it over a large circular area chosen to remove the outer part of the slices, and also to reduce the impact of beam hardening (Desrues et al., 2006). Figure 1a shows X-ray CT values in Hounsfield units (HU) for different depths. Figure 1b shows CT values obtained from the $\mathrm{HU}$ values by conversion to an 8 -bit gray scale. In the depth interval from 2862 to $2870 \mathrm{~m}$, there is a clear signature of cyclicity. In the sandstone interval (2870-2874.3 $\mathrm{m})$, the X-ray CT values are lower and the cyclicity disappears.

Figure 2 shows CT images from shale and marlstone samples. Shales are related to dark images with smaller densities and velocities; marlstones are at the other extreme, and in between there is a gradation between the two. These changes are caused by variation of the amount of calcium carbonate which is enhanced in CT imagery owing to the relatively high atomic number of calcium. Using an empirical relation-

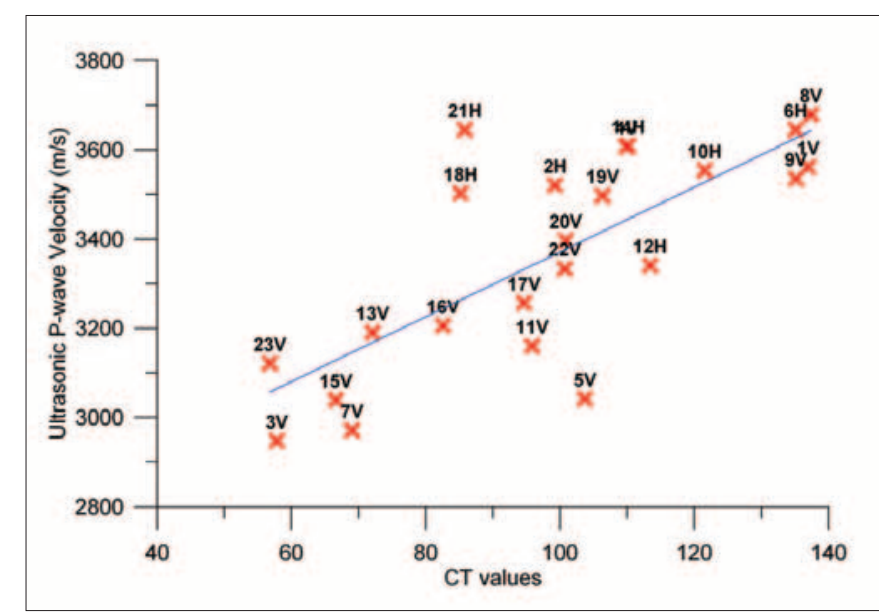

Figure 3. Ultrasonic P-wave velocity measured along the vertical and horizontal directions from core samples versus $X$-ray $C T$ values, obtained at the same depth $\left(R^{2}=0.57\right)$.

ship between X-ray CT values and ultrasonic P-wave velocities measured from core samples at effective pressure 3000 psi (reservoir pressure) at the same depth, we translate the Xray $\mathrm{CT}$ values to the so-called X-ray CT velocities (Figure 3).

Due to the limited number of core sample measurements, a single crossplotting does not translate the X-ray CT values to the whole spectrum of velocity variations. Instead, it would generally follow the small-scale (high-frequency) pattern of sedimentary cyclicity and would not pick up the large-scale (low-frequency) velocity variations. An alternative approach, which we used here, is feeding the largescale velocity variations evident from the sonic logs into the mapping. To do so, we mapped CT velocities using a single crossplot and subtracted them from their mean and superimposing on the low-frequency velocity model extracted from the sonic logs. This procedure makes it possible to compare directly the seismic response of a stack of elastic layers based on CT velocities and densities with that computed from the well $\operatorname{logs}$ as demonstrated below. Velocity and density pro- 


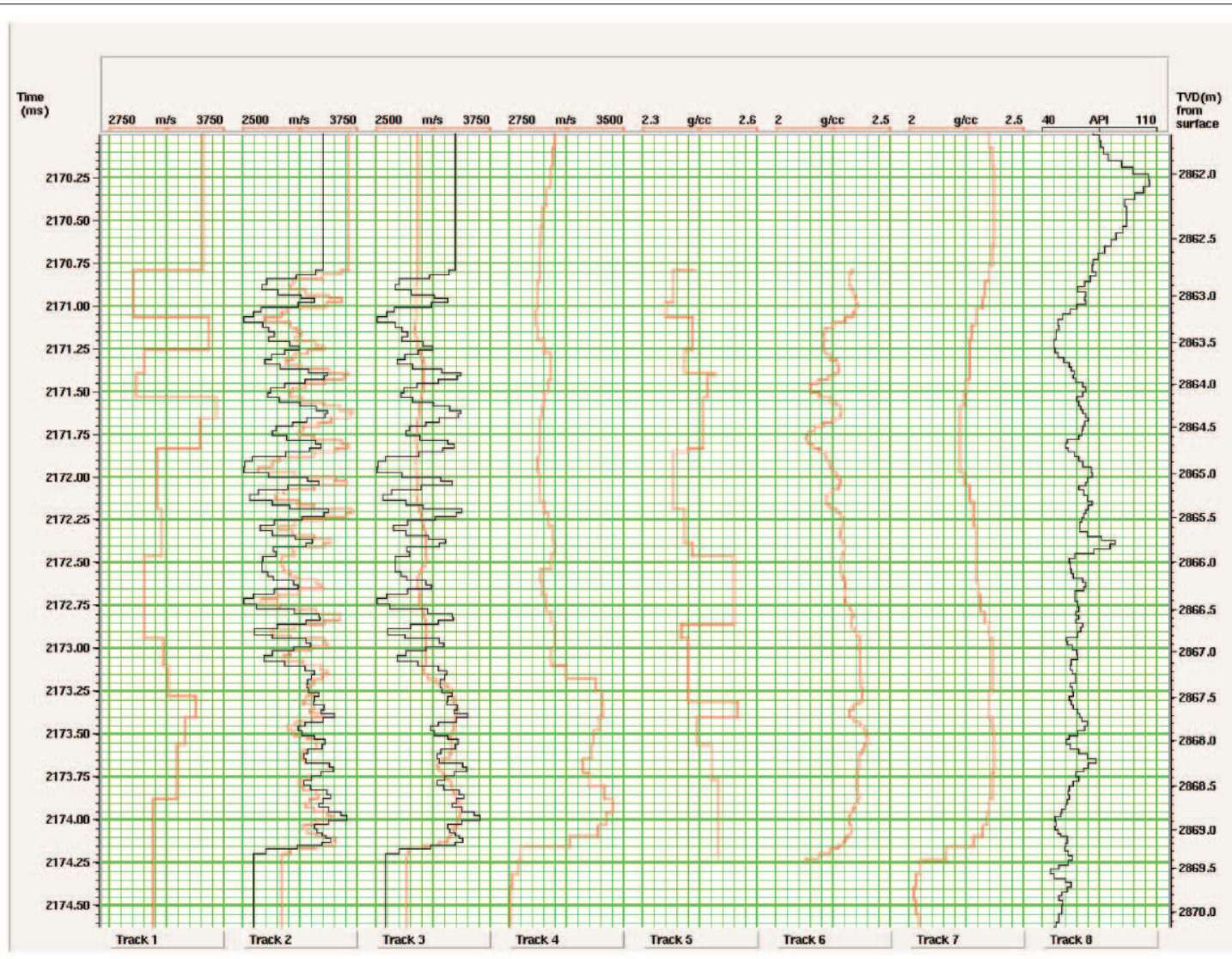

Figure 4. Tracks 1-4: ultrasonic P-wave velocity from core plugs at effective pressure (3000 psi); velocities computed from CT images before (red) and after correction for low frequency (black); velocities computed from CT images after correction for low frequency superimposed on the high-resolution log for comparison; and standard sonic log. Tracks 5-7 are densities from core samples, high-resolution, and standard logs. Track 8 is a high-resolution gamma-ray log.

Figure 5. Autocorrelation function of high-resolution gamma-ray log (green line), density log (purple line), P-wave log (dark brown line), and $C T$ velocities (red line) for the depth interval $2862.75-2869.40 \mathrm{~m}$. The upper graph shows the periodogram of the $C T$ velocities. The periodogram's main pick in the wavenumber domain maps to a 37.6$\mathrm{cm}$ correlation lag in the autocorrelation function.

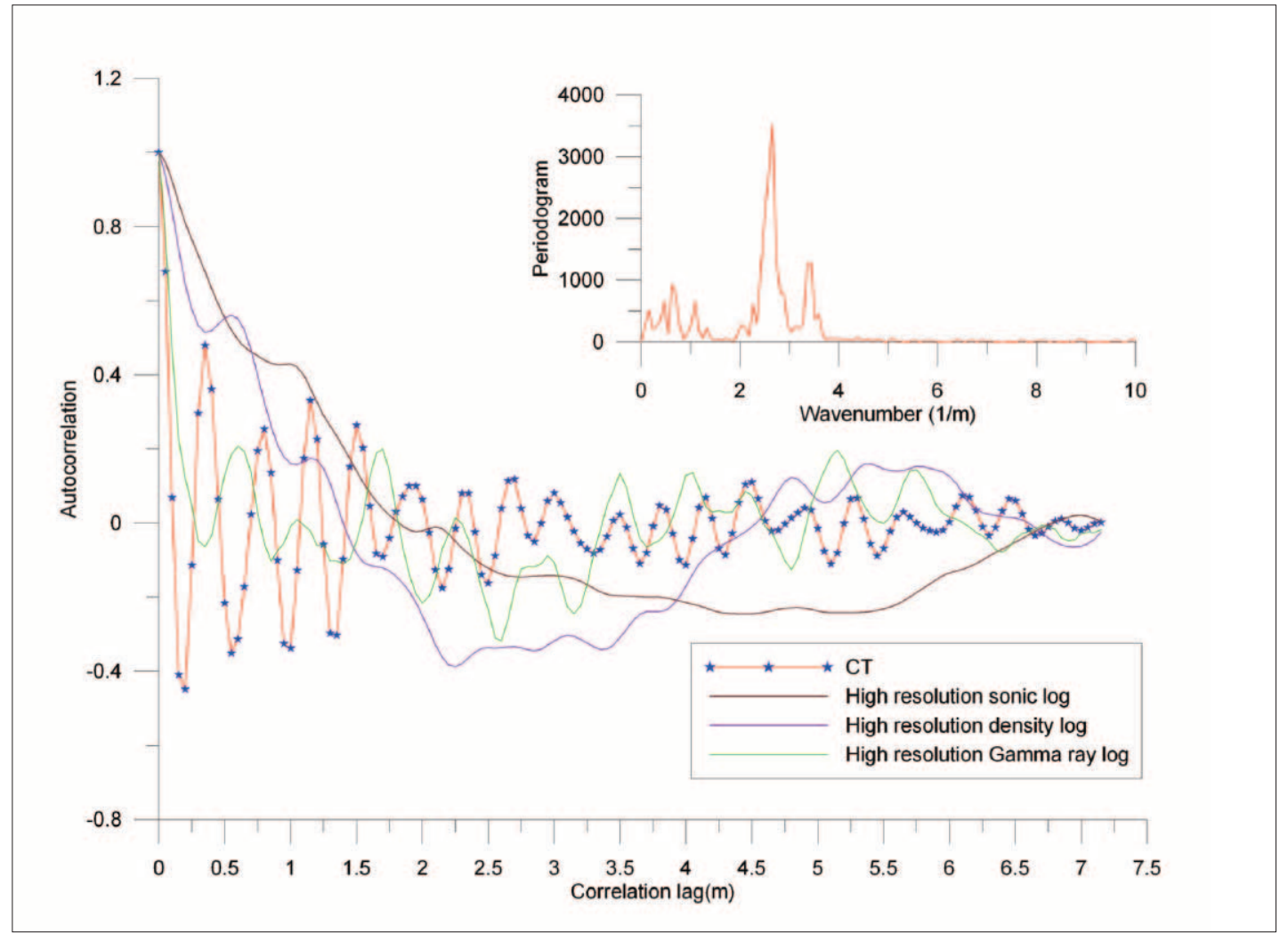




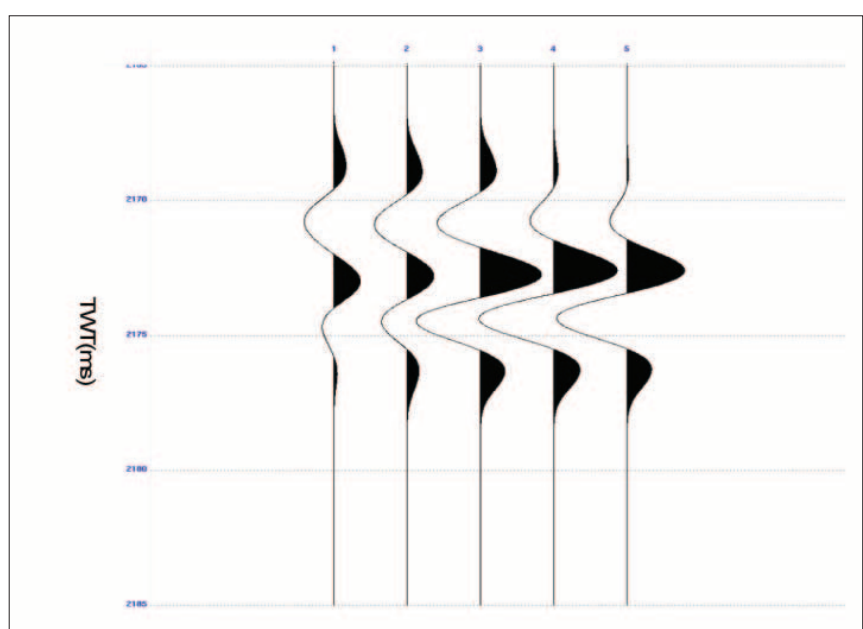

Figure 6. Zero-offset synthetic seismograms computed from the velocity-density profiles in Figure 4. (1) Ultrasonic P-wave velocities and core densities. (2) CT velocities before correction. (3) CT velocities after correction. (4) High-resolution sonic log. (5) Standard sonic log and correspondent density logs. Core sample densities were used in computing traces 2 and 3. All logs blocked at $5 \mathrm{~cm}$.

files in depth are shown in Figure 4. The corresponding time axis is constructed from the compaction trend. Ultrasonic measurements, CT velocities before and after correction for low-frequency, high-resolution and standard sonic logs are shown in the left tracks; densities from core samples, highresolution and standard logs are shown in the right tracks.

Spectral analysis and correlation functions reveal interesting features of the sedimentary cyclicity. Figure 5 shows the autocorrelation function for the CT values and highresolution gamma, density, and sonic logs. The gamma-ray autocorrelation function has similar behavior with that computed from the CT values. This is expected as $\mathrm{CT}$ values also reflect clay content. They show smaller correlation length which represents the high variability of clay sedimentation. From the other side, density and in particular sonic velocity have larger correlation lengths as expected. They are less variable as sediments accumulate. This example demonstrates the variability of the correlation length for different properties that should be accounted for when building geomodels. The inset in Figure 6 shows the periodogram of CT values, revealing the periodicity of the sequence. The main pick in the periodogram corresponds to the spatial wavenumber of the dominant period. Translating this into the space domain gives a correlation length equal to $37.6 \mathrm{~cm}$.

To understand the impact of small-scale sedimentary features on seismic wave propagation, we have computed a series of synthetic seismograms using the Zoeppritz equations for stacks of layers featuring different spatial scales (Figure 6). The small thickness of the investigated depth interval (7 m) limits the observability of small-scale features at seismic frequencies. Therefore, we used a Ricker wavelet with dominant frequency of $200 \mathrm{~Hz}$ in our simulations. Assuming stationarity of the sedimentary sequence, the result of these simulations could be considered as equivalent to the wavefield response of a $50-\mathrm{Hz}$ impulse propagating through a sequence of $28-\mathrm{m}$ thickness. The seismic response from the

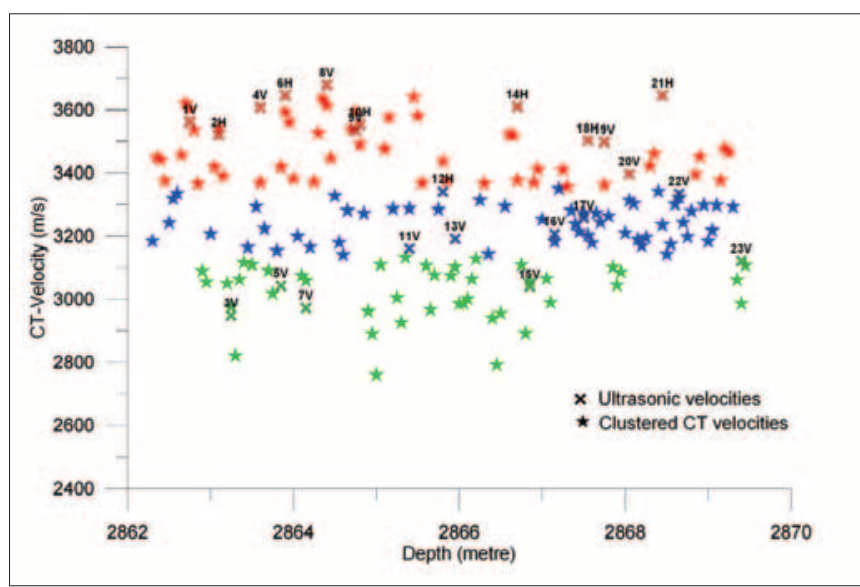

Figure 7. Clustering the CT velocities into three groups using the $K$-means technique. Red stars correspond to marl and green to shale facies. An intermediate shale-marl facies is shown as blue stars. Crosses are ultrasonic P-wave velocities from core samples measured at 3000 psi.

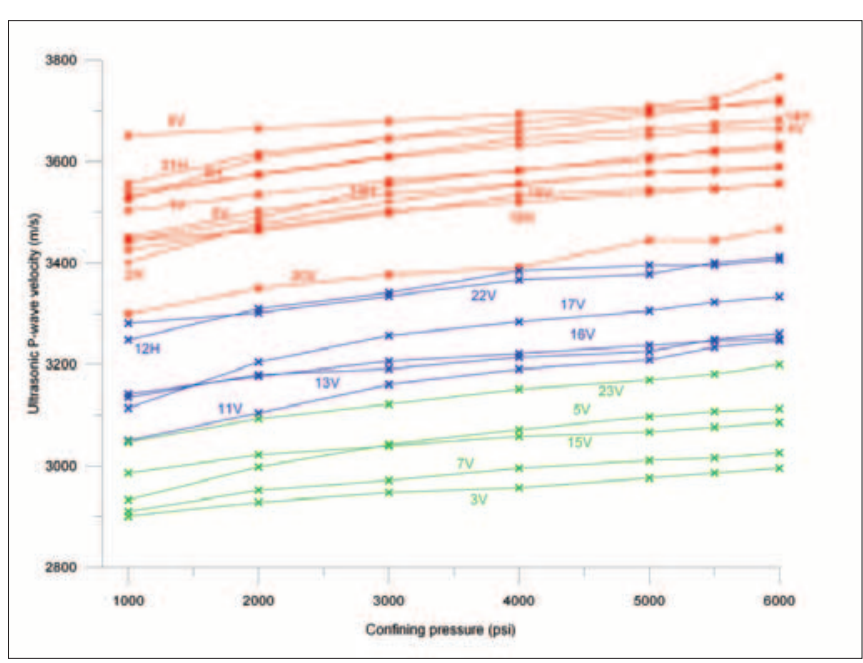

Figure 8. Ultrasonic P-wave velocities (23 plugs) versus confining pressure measured in the laboratory. Green curves represent shales and red curves marlstone. Blue curves represent an intermediate shale-marl lithofacies. Facies classification gives more geological insight to the geomechanical properties of these core samples.

core-scale model is quite different from the log-scale model (Figure 6). The CT-based model gives an intermediate response. In particular, CT-based models before and after correction for low-frequency spatial variations give similar results to the core- and log-scale profiles, respectively. Not surprisingly, this shows that the low-frequency component of the medium (i.e., large-scale features) plays a more profound role within the seismic frequency band than the highfrequency features. Nevertheless, we can still observe some changes in the waveform especially for early arrivals if the CT scale features are included.

Implication of CT velocities for the stress sensitivity in the overburden

In the previous section, we noticed that the CT images give a precise picture of lithofacies of the cores. These litofacies- 
which we already mapped into seismic velocities using the ultrasonic measurements-can feed back the facies information into the core samples. To do so, we need to classify the CT images into different facies. We used a K-means clustering technique to classify the $\mathrm{CT}$ velocities into three main groups: marl, shale, and an intermediate group. Figure 7 shows three clusters of CT velocities in red, blue, and green. Due to periodicity of sediments, all three facies are extended across the borehole. Each cluster is represented by a mean and its standard deviation. Red corresponds to marl, green corresponds to shale facies, and blue corresponds to an intermediate shale-marl facies. Every core sample with ultrasonic velocity measured within the above ranges could fall into one of these three lithofacies classes.

The majority of known Campos Basin mature reservoirs under development are sandstone turbidites containing thick intra-shale layers (Bruhn et al., 2003). As shale and sandstone layers have different geomechanical properties, their identification and characterization are essential for time-lapse studies. It has been a routine practice in Petrobras to measure the dynamic elastic properties of reservoir sands and, in some cases, of the overburden from core samples at different pressure. The potential use of the CT images in revealing the thin shale and marl layers is shown in Figure 8. This also shows how the stress sensitivity is different for these fine layers. Given the mean and standard deviation for each lithofacies group derived from CT velocities, each core sample has been classified in one lithofacies group according to its ultrasonic P-wave velocity at pressure 3000 psi in Figure 7. Figure 8 also shows that velocity-pressure dependency is very much associated with the lithology of the core samples. For more details about the impact of thin impermeable shale and marl layers on seismic response during the depletion and injection in Campos Basin, readers are referred to Grochau (2009).

\section{Conclusion}

The computed velocities from CT images show clearly the cyclic behavior with much higher resolution than the sonic log. Vertical variation of X-ray CT values shows a clear pattern of sedimentary cyclicity with a spatial period of 37.6 $\mathrm{cm}$ estimated from the autocorrelation function and the periodogram. Within the seismic frequency range, there is a slight change in wavefield response if fine-scale sedimentary cyclicity is accounted for. The correlation length for different petrophysical properties is different and this needs to be considered when building geomodels which take into account the spatial correlation. CT images also show their potential to discriminate thin layering of different facies through clustering which helps redefining the geomechanical properties of different facies for stress sensitivity studies. TLE

\section{References}

Desrues, J., G. Viggiani, and P. Besuelle, 2006, Advances in X-ray tomography for geomaterials: International Workshop on X-ray CT for Geomaterials.

Mees, F., R. Swennen, M. Van Geet, and P. Jacobs, 2003, Applications of X-ray computed tomography in the geosciences: Geological Society London Special Publications, 215, 1-6.

Murphy, W. F. I., J. N. Roberts, D. Yale, and K. W. Winkler, 1984, Centimeter scale heterogeneities and microstratification in sedimentary rocks: Geophysical Research Letters, 11, 697-700.

Rothwell, R. G. and F. R. Rack, 2006, New techniques in sediment core analysis: an introduction: Geological Society London Special Publications, 267, 1-29.

Bruhn, C. H. L., C. D. Lucchese, J. A. T. Gomes, and P. R. S. Johann, 2003, Campos Basin: Reservoir characterization and management - Historical overview and future challenges: Offshore Technology Conference Expanded Abstracts.

Grochau, M. H., 2009, Investigation of pressure and saturation effects on elastic parameters: an integrated approach to improve timelapse interpretation: Lambert Academic Publishing.

Acknowledgments: We acknowledge Petrobras for log and core data, and permission to publish this paper. We also thank the following people for their ideas, opinions and comments: Ana Moliterno, Armando Scarparo Cunha, Gilberto Albertao, Guilherme Vasquez, and Osni de Paula of Petrobras; and Maxim Lebedev of Curtin University of Technology. We acknowledge CGGVeritas for access to the Hampson-Russell software suite.

Corresponding author: marcosgrochau@petrobras.com.br 